\section{Cutting efficiency for minimally-invasive endo treatments}

For endodontists, COLTENE offers the MicroMega One RECI reciprocating file.

The MicroMega One RECI delivers unparalleled cutting efficiency, also:

$\rightarrow$ Flexibility

$\rightarrow$ Controlled memory

$\rightarrow$ Good resistance to cyclical fatigue

$\rightarrow$ Increased safety

$\rightarrow$ Thinner file to minimise healthy tooth removal.

The design increases the centring ability of the file in the canal, with a s-shaped section in the medium and coronal sections to increase debris removal. It is also single-use, for added peace of mind. The MicroMega One RECI will allow you an excellent compromise between flexibility and cutting effect, so you can initiate predictable, stable and successful root canal treatment with confidence.

For more on COLTENE visit www. coltene.com,email info.uk@coltene.com or call 08002545115.

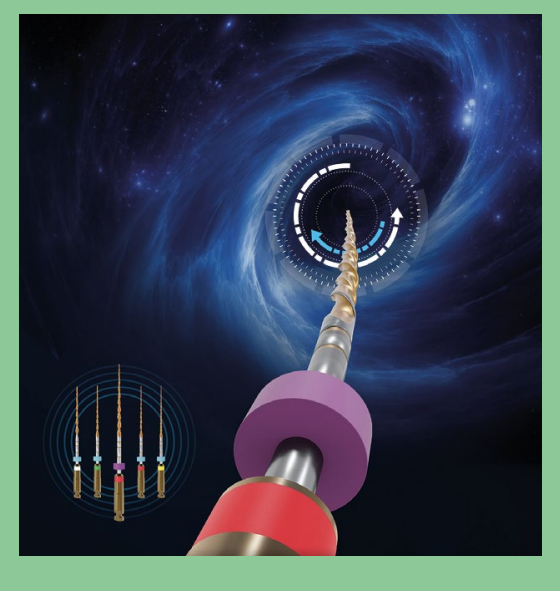

\title{
The new customer portal
}

Keeping compliant with your waste management is essential. With myInitial, the newly revamped customer portal from Initial Medical, both the pursuit of sustainability and compliance are easier than ever before.

myInitial offers information at your fingertips and includes a comprehensive digital document library, meaning

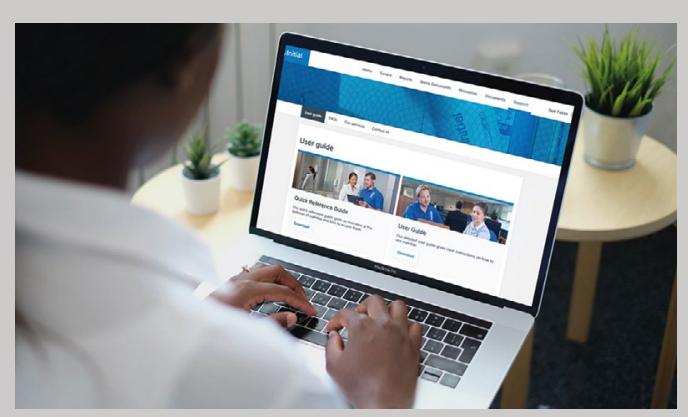

that you can negate paper waste and instantly access all of your records in one convenient place. There is a new section for e-waste documentation, and you can also use the portal to view your eBilling, look at technical product selections and link directly with Initial Medical's online shop. myInitial provides a fast and convenient way to stay on top of your waste management and infection control needs, and also assists with auditing, as the portal can be used to prove service delivery, with access to all your hazardous waste documentation and licenses provided.

For further information visit https://www.initial.co.uk/myinitial/ or call 08708504045 .

\section{Chairside restorations made easy}

With many patients now looking for sameday treatment, it pays to be able to offer a complete chairside solution.

With CEREC Primescan and Primemill available from Clark Dental, you can provide patients with high-quality chairside restorations with ease.
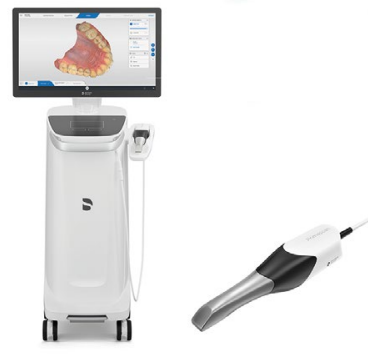

The scanner captures exceptionally accurate intraoral scans that, using the inbuilt CEREC software, can be instantly transferred to the Primemill milling system. This versatile piece of tech can then be used to design and produce restorations made from a number of materials, providing the flexibility necessary to suit a vast array of indications.

Discover the best way to provide single-visit dentistry for your patients today by contacting Clark Dental.

For more information call Clark Dental on 01268733 146, emailinfo@clarkdental. co.uk or visit www. clarkdental.co.uk.

\section{Make 2022 the year that you grow your business and boost profits}

Stop spending precious time and stress on your payroll - outsource it to specialist provider Wagemate.

Wagemate's tailored solutions work for any-size practice. We will give you:

$\rightarrow$ Efficient and accurate payroll, hassle-free

$\rightarrow$ Peace of mind, with all data stored securely in the Cloud $\rightarrow$ Custom reports for extra insight

$\rightarrow$ A convenient online portal

$\rightarrow$ A dedicated account manager

$\rightarrow$ A guarantee of full compliance with HMRC.

With Wagemate, no more extended working hours desperately trying to get payroll done.
What are you waiting for! Make Wagemate a part of next year's success.

To better manage your payroll, contact payroll specialists Wagemate on 03330102102 or via email at info@wagemate.com.

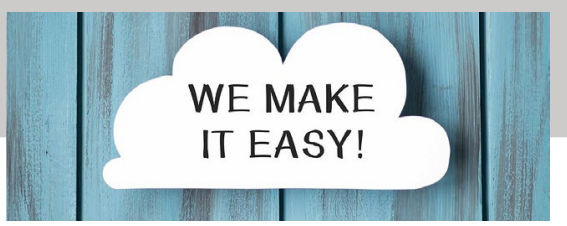

